When I saw her the breast was atrophied and the nipple had disappeared. There wes a large slonghing nodular vicer with irregular edges, measuring 8 by $5 \mathrm{~cm}$., over the breast. irregular edges, measuring 8 by $5 \mathrm{~cm}$., over the breast. enlarged glands in the axilla and supraclavicalar region. enlarged glands in the axilla and supraclavicalar region. Radium was applied without lead to the ulcer, and through 1 mm. lead all over for about forty-eight hours. This relieved the pain, and the discharge and haemorrhage, which had been profuse, nearly ceased. The improvement was so great that a month later the patient herself asked for a further course of treatment. By then the nodules on the ulcer bad almost in dials disappeared, the surface was clean, and to grow round the edges. The surrounding growths and glands had also diminished. Unfortunately, during the second course of treat. ment an acute attack of plearisy, probably of a septic nature, set in, and she died after a three days' illness. The last two months of her life, however, were at least made tolerable.

In the treatment of these cases I have followed the originators of the method in using lead screens. Recently for growths in or immediately ander the skin I have employed another method which I think acts as well and saves valuable time. It consists in placing the applicator either without lead or with a thin lead screen, at some distance, $\frac{1}{2}$ in. or more, away from the skin. As the rays are divergent a much larger area, about four times the size of the applicator itself, can now be irra. diated by the more penetrating and $f$ ffective of the rays, the softer and skin.damaging rays being cut off by the air space and layers of lint or cotton-wool. In deeply-seated growths the radium mast be placed on the skin, if it is intact, so as to be as near to the tumour as possible, and the skin must then be protected by lead, 2 or $3 \mathrm{~mm}$. thick, to prevent damage from the prolonged exposures required. In these cases, however, there is no doubt that much better results are obtained by burying the radium in the substance of the tumour. I have found no benefit result in the fow cages in which radium emana. tions have been employed, or in which radium bromide has been given internally. In all my cases $x$ rays have been applied to the surrounding parts in addition to the radium treatments.

There is no doubt that some varieties of cancer are much more responsive to radium than others. With few exceptions it is in the slow.growing cases that it acts best, and in which a dimination in size may be expected. Unfortunately we have no statistics of the number of cases in which it fails. That failure occurs not infrequently even in those treated on the Continent with large quantities of radium is well known. We know also that it does not always care the comparatively benign rodent ulcer or prevent its recurrence. I have seen a rodent reappear as late as three years after its apparent cure by radium. As my earliest successful case of cancer was treated only eighteen months ago, it is too soon to speak of the ultimate result. Recently Nahmmacher ${ }^{2}$ reported a case of carci. noma with no recurrence as late as three years after radium treatment.

At present the position of radium-therapy seems to be that while it is of undoubted value in many cases, its chief function is in aiding and not in excluding the other recognized methods of treatment. Until it can be proved that relapse and metastasis are not more common after regression from radium than after excision, the method must be reserved for those cases in which operation is contraindicated and for recurrences.

Apart from the question of the curative effect of radium, there is one point of practical importance which deserves attention. It is th it in the cases in which radium acts beneficially it acts at once. Within fourteen days of the beginning of the treatment an unquestionable diminution in size will be found in all cases. in which radium is able to exert a regressive effect. Occasionally this decrease is seen as early as the third or fourth day. If no improvement is apparent in this time further treatment is useless, except, perhaps, for its palliative effect.

There appears to bo no other certain means of foretelling in the individual case the result of radium treatment, and I have found this test application very useful in determining the advisability of a prolonged and necessarily expensive course of treatment. It will be of still greater value, if radium falfils expectations and its results are found to be permanent, in deciding the question of operation.

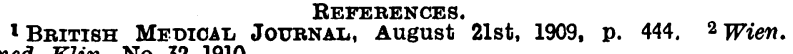
med. Klin., No. 32, 1910 .

\section{CURATIVE INFLUENCE OF ROENTGEN RAYS} IN MALARIA.

BY

LIEUT.COL. BRUCE SKINNER, M.V.O., R.A M.C. AND

LIEUT. H. W. CARSON, R.A M.C.

TrE influence of the Roentgen rays in changing the pathological conditions in certain diseases (such as leucocythremia and lupus) gave one of us the jdea that the application of $x$ rays over the spleen should bave some beneficial effect in cases of malarial fever, where one of the most distressing symptoms is the pain caused by engorgement of the spleen. It was thought that the rays might have some action upon the malaria parasite either directly on the parasite or indirectly by causing changes within the blood which should destroy the parasite.

It seemed not unlikely that the blood changes which are known to be induced within the body after exposure to $x$ rays would stimulate the leucocytes to destroy the parasite, or that the altered serum would act in such a manner as to make the continued action of the parasite impossible.

The $t$ ffect of heat applied over the splenic area in relieving the pain attendant upon an attack of malarial fever gave the idea that $x$ rays also might have therapentic action as the immediate effect of their similar application.

That these conjectures were not without base is evidenced by the following cases :

A. Cases of Malarial Fevers.

Case I.-Lance-Corporal S., 1st Royal Munster Fusiliers, admitted with a temperature of $104^{\circ}$; B. T.; spleen slightly enlarged and tender. For two days morning temperature rose to $104^{\circ}$. Had quinine by the mouth with no result; exposure five minutes Temperstare dropped to $97^{\circ}$ with no subsegue minuteand the pain and tumour diseppeared.

CASE II.-Private H., 9lst Battery, R.F.A.; B. T. ; temperaCASE II.- Private H., 9lst Battery, R.F.A.; B. T.; temperature on admission $104^{\circ}$; some enlargement of spleen with Temperature became subnormal, pain and tumour disappeared, Temperature becam

no subsequent rise.

CASE III. - Gunner W., 91st Battery R.F.A.; B. T. On admission temperature was $104^{\circ}$. He was put on quinine by the mouth. Temperature rose to $104^{\circ}$ next day, and on the next to $104.4^{\circ}$. His spleen was slightly enlarged and tender on pressure, which persisted. Exposure five minutes on third morning. Temdisappeared

CASE IV.-Lance-Corporal P., 2nd North Stafford Regiment; B. T. On admission temperature $103^{\circ}$; the spleen was en)arged 2 in. below costal margin, and painfal. Exposure five minutes. The pain was relieved immediately, and the enlargement was The pain was relieved immed to subnormal. The next morn. lessened ; temperature dropped to sabnormal. The next morn ing there was a slight rise of temperature. Exposure three minutes. Enlargement of spleen disappeared totally, and temperature

No quinine. admitted having had ague the day before. Temperature normal. Spleen enlarged 2 in. below costal margin; very painful. Exposure five minutes. The enlargement and pain disappeared and temperature remained normal without any further rise. No retarn of pain. Convalescent. No quinine.

\section{B. Cases of "Peshauar" Fever.}

CASE vi.-Gunner B., 86th Battery, Royal Garrison Artillery; B.T. admitted collapeed. Haemorrhage from the bowels B.T.; admitted collapsed. Haemorrhage from the bowels; temperature normal; spleen not enlarged. Exposure five minutes. No return of haemorrhage; temperature remain CASE vir.-Private McS., lst Royal Munster Fusiliers; B.T. admitted in collapsed condition. Haemorrhage from bowel temperature 99. Exposure five minntes. No return o haemorrhage. On the second day the temperature rose to $101^{\circ}$ Given exposure of three minutes every day. On the fourth day Gemerre during this time. No quinine.

C. Malaria with Cerebral Symptoms.

CASE VI - Private K., lst Royal Munster Fusiliers, admitted CASE VII. - Private K., 1st $8^{\circ}$; collapsed. wo no enlargement ol spleen, rent type. Had one injection quinine on second morning, and guinine by the mouth on the third and lourth. No satisfactory resulta; temperature still remained high, and the mental symptoms persisted. Exposure of rise of temperature. 
D. Miscellaneous.

CASE IX.-Sergeant C., lst Royal Munster Fusiliers; second admission for M. T.; temperature $103^{\circ}$. Quinine given at first and discontinued when spleen was found enlarged 2 in. below costal margin; hard on palpation, with well-defined border painful. Exposure five minutes on two consecutive deys. Result Immediate relief of pain and disappearance of enlargement temperature dropped to subnormal after second day; no further rise in temperature; convelescent.

Case X.-Gunner'P., 9lst Battery R. F. A.; admitted with B. T. X.-Ganner Pojo . Th splenic region; spleen enlarged below costal margin. Exposure splenic tumour; temperature dropped to subnormal, no further rise; convalescent.

CASE XI.-Bombardier L., 9lst Battery R. F. A.; admitted with B. T. ; temperature $100^{\circ}$. Complained of dragging pain in region of spleen; spleen enlarged 1 in. below costal margin. Exposare three minutes; relief of pain; disappearance of splenic tumour; temperature dropped to subnormal, no further rise; convalescent

Remarks

Oar experience has been that the application of $x$ rays in cases of malarial fever relieves splenic pain and reduces recent engorgement; that the temperature falls and does not usually rise again ; and that recovery is not attended by the anaemia usually present in cases treated with quinine. We have not had to fall back upon quinine in cases treated by the $x$ rays, while we have had cases which resisted quinine and yielded promptly to the rays (quinine being discontinued)

We have 5 cases (natives) of chronic induration of spleen (malarial) under treatment, but the progress made has not been sufficiently marked to enable us to make any definite statement as to the special value of $x$ rays in such cases. Bat we are so impressed with the results in malarial fever cases that we have prepared this record in the hope that our experiences may be obtained by others, and on a more extended scale.

\section{THYROID EXTRACT IN CARCINOMA.} BY

\section{E. HUGHES JONES, M.D.} RHYL.

ALTHODGH organo-therapy in some form or another has existed from most ancient times, even amongst savages, the method as at present practised is of recent origin, and of all extracts thyroid gland is still the most successfully used, and for certain conditions, such as myxoedema and cer tain forms of goître, a specific, even more so than potassium iodide for syphilis or the salicylates for rheumatism. There are many other conditions in which the gland has been more or less successfally employed, though perhaps without definite specific action-for instance, oedema, psoriasis, uterine fibroid, some forms of retarded development in children, and many other cases associated with defective metabolic processes-which is well illustrated by the following most striking case of multiple car cinoma of the skin and subcutaneous tissue. I am aware that this is only a single instance, bat the result was so gratifying that a record of the notes of the case may prove interesting.

The patient, a widow aged 61, gave the following history : In November, 1899, she had a large pimple in the right axilla, and at the same time two nodules below the skin on the left side of the chest in the axillary line. The latter seem to have disappesred after the application of some ointment. The lump under the right axilla, however, continued to grow, until it attained the size of an ordinary marble, of a dark purple colour and at times this was very painful. At this period the colour, health remained extreme cold associated with a greenish pallor of the face. The extreme cold associated with a greenish pallor of the face. The Jump under the right axilla became so large and painful that in
June, 1900, she went to see Mr. Robert Jones, of Liverpool, who advised immediate operation. This was done. In October of the same jear she again consulted him for a growth under her left breast. She was urged to go again in a fortnight, to have this also removed, but, as in the meantime another growth occurred in the left side of the upper part of the abdomen, the patient was discouraged and did not go. During the months that followed seversl other fresh growths appeared under the skin, two on the right side of the chest, one on the front of the chest above the breast, two on the left side of tho cheat, and chest af and growths in all, varying in size from a walnut to a Tangerine growths
By this time her general health was suffering severely. I saw her in June, 1901, and found the growths as above described The growth in the right axilla was the largest of all, fixed and painful, and was the size of a tennis ball; it prevented the arm from being brought to the side, and had recurred at the site of the scar of the previous operation performed by Mr. Rnbert Jones (in June, 1900). The other growths were smaller, about the size of filberts and walnuts. They were not painful, bu were tender on pressure and hard

characteristic of scirrhous cancer.

The larger growth (axillary) was to all appearances not far from ulceration and breaking down. The patient appeared to be very anaemic, having a sallow greenish-yellow colour; her pulse and respiration were quickened, and her temperature varied from about $99^{\circ}$ to $101^{\circ}$. Sickness was frequent; the appetite was very poor-she was scarcely able to retain anything. The patient had lost 3 st. in weight.

As she had been operated on twelve months previously, with the unfortunate result mentioned, and owing to the dissemination of the growth and her feeble state of health, it was useless to suggest further operative interference, so I decided to try the effect of thyroid medication. Owing to her enfeebled state of health I administered tabloids of thyroid gland with extreme caution, "starting with grains $v$ daily, gradually increasing the dose to grains $x$, and finally to grains $x v$ daily.

To my surprise the patient quickly showed signs of improvement ; the palpitation, sickness, and emaciation gradually disappeared pari passu with the gradual dis appearance of the growths. At the end of Augast, 1901, the growths had entirely disappeared, the patient was practically well and had recovered her lost weight of 3 st., and up to the present date is quite well, not having suffered in any way from them since. I was so gratified with this result that I almost doubted the nature of these growths, so I wrote to Mr. Robert Jones of Liverpool, in December, 1903, for his opinion of the growth he had removed in 1900. The following is his answer to my inquiry :

It was unquestionably a carcinoma, although I cannot quite recollect any of the pathological details. It was examined by a couple of men besides myself. Some time later there seemed to be a recurrence of the growth trouble, and I recommended removal of the lump. However, she would not agree to that, and $I$ have often wondered what happened to it. This was some years ago; can you let me know in what spot the growth you will find in the fold of the axilla, or is it in the bress you will
tissue?

After reviewing the results of thyroid administration obtained by other observers, much less after the result in the case I have jast recorded, any impartial observer must conclude that thyroid organo-therapy cannot in any sense supersede the well-recognized methods of surgical procedure in operable carcinoma. The free removal of the growth during the operable stage must stand as the sonndest and most hopefal measure of curative treatment. When, however, complete radical treatment is out of the question, and when operative measures are re fused by the patient, even in the operable stage, thyroid administration offers some hope of checking the rapidity of the growth, favouring spontaneous cure, and possibly achieving the slow but absolute disappearance of the growth.

There are now on record a number of well-authenticated cases of carcinoma, in addition to my own case, which have to all appearance entirely disappeared under the administration of thyroid extract. Their numbers are not great, but they are sufficiently striking to lead me to conclude that the association of thyroid administration with the cure is more than a mere coincidence.

A still larger number of cases of carcinoma have been recorded where thyroid administration was followed by disappearance of secondary nodules, increase of weight, loss of pain, and other signs of marked local and general improvement, but not complete cure of the growth. In these cases trested by thyroid there appeared to be established a negative phase of growth in the neoplasm, daring which the nodules or mass ceased to grow-or retrogressed-and in many cases underwent a spontaneous cure.

Many of the cases which were thus favourably influenced by organo-therapy had double oöphorectomy performed previous to the administration of this animal extract. Double oöphorectomy found its great advocate in Beatson, and was applied particularly to women below the menopause. Beatson, supported by other observers such as Herman, Stiles, Chicken, McAdam Eccles, and 